\title{
Amino Acid Metabolism during Prolonged Starvation
}

\author{
Philip Felig, Oliver E. Owen, John Wahren, and George F. Cahill, Jr. \\ From the Elliott P. Joslin Research Laboratory, Boston, Massachusetts 02215, \\ the Cardiovascular Unit, the Departments of Medicine and Surgery, Harvard \\ Medical School, Boston, Massachusetts 02115, the Peter Bent Brigham \\ Hospital, Boston, Massachusetts 02115, and the Diabetes Foundation, Inc., \\ Boston, Massachusetts 02215
}

\begin{abstract}
A B S T R A C T Plasma concentration, splanchnic and renal exchange, and urinary excretion of 20 amino acids were studied in obese subjects during prolonged (5-6 wk) starvation. Splanchnic amino acid uptake was also investigated in postabsorptive and briefly (36-48 hr) fasted subjects.
\end{abstract}

A transient increase in plasma valine, leucine, isoleucine, methionine, and $\alpha$-aminobutyrate was noted during the 1st wk of starvation. A delayed, progressive increase in glycine, threonine, and serine occurred after the 1 st 5 days. 13 of the amino acids ultimately decreased in starvation, but the magnitude of this diminution was greatest for alanine which decreased most rapidly during the 1 st week of fasting.

In all subjects alanine was extracted by the splanchnic circulation to a greater extent than all other amino acids combined. Brief fasting resulted in an increased arteriohepatic venous difference for alanine due to increased fractional extraction. After 5-6 wk of starvation, a marked falloff in splanchnic alanine uptake was attributable to the decreased arterial concentration. Prolonged fasting resulted in increased glycine utilization by the kidney and in net renal uptake of alanine.

It is concluded that the marked decrease in plasma alanine is due to augmented and preferential splanchnic utilization of this amino acid in early starvation resulting in substrate depletion. Maintenance of the hypoalaninemia ultimately serves to diminish splanchnic uptake of this key glycogenic amino acid and is thus an important component of the regulatory mechanism whereby hepatic gluconeogenesis is diminished and protein catabolism is minimized in prolonged fasting. The altered renal ex-

A preliminary report of part of this work has appeared in abstract form (1).

Dr. Felig is recipient of U. S. Public Health Service Special Postdoctoral Fellowship, 5-F3-AM-36-069.

Received for publication 24 August 1968 and in revised form 31 October 1968. traction of glycine and alanine is not due to increased urinary excretion but may be secondary to the increased rate of renal gluconeogenesis observed in prolonged starvation.

\section{INTRODUCTION}

Man's survival of prolonged starvation is predicated upon a remarkable ability to conserve the relatively limited body protein stores while utilizing fat as the primary energy-producing fuel. Previous studies from this laboratory have documented this conservation of body protein as evidenced by decreased urinary nitrogen excretion (2), a marked attenuation of hepatic gluconeogenesis determined by direct measurements of splanchnic glucose production (3), and adaptation of brain to ketone acid utilization thereby sparing amino acid conversion to glucose for terminal oxidation (4). While these studies suggest a well integrated control of fuel utilization, the mechanism whereby gluconeogenesis is attenuated and protein is conserved remains obscure. Direct inhibition of hepatic amino acid uptake, primary blockade of amino acid release from peripheral protein reserves, or both may be operative. The importance of elucidating the mechanism controlling catabolism in starvation is underscored by the likelihood of its providing insight into the metabolic derangement responsible for the severe protein wasting of uncontrolled diabetes, sepsis, and trauma.

In the present study we have measured individual plasma free amino acid levels in obese persons after various intervals of fasting. In addition, net splanchnic and renal amino acid exchange have been studied by the venous catheter technique after 5-6 wk of starvation. Finally, since limited in vivo data are available on hepatic amino acid uptake (5), subjects were also studied in the postabsorptive state and after a $36-48 \mathrm{hr}$ fast. 
TABLE I

Clinical Data on Obese Subjects Studied during Prolonged Starvation

\begin{tabular}{|c|c|c|c|c|c|c|c|c|}
\hline \multirow[b]{2}{*}{ Subject } & \multirow[b]{2}{*}{ Age } & \multirow[b]{2}{*}{ Sex } & \multirow[b]{2}{*}{ Height } & & \multirow{2}{*}{$\begin{array}{l}\text { Duration } \\
\text { of fast }\end{array}$} & \multicolumn{2}{|c|}{ Weight } & \multirow{2}{*}{$\begin{array}{l}\text { Deviation } \\
\text { initial wt } \\
\text { from pop- } \\
\text { ulation } \\
\text { ideal wt* }\end{array}$} \\
\hline & & & & & & Initial & Final & \\
\hline & $y r$ & & $\mathrm{~cm}$ & & days & \multicolumn{2}{|c|}{$\mathrm{kg}$} & $\%$ \\
\hline $\mathrm{AB}$ & 19 & $\mathbf{M}$ & 183 & & 35 & 125.2 & 101.8 & 71 \\
\hline $\mathrm{FF}$ & 32 & $\mathbf{M}$ & 180 & & 39 & 127.2 & 105.6 & 66 \\
\hline GS & 43 & M & 183 & & 40 & 131.1 & 106.0 & 66 \\
\hline \multirow[t]{4}{*}{ FN } & 49 & M & 178 & No. $1 \ddagger$ & 38 & 132.6 & 109.8 & 91 \\
\hline & & & & No. 2 & 40 & 110.2 & 87.5 & 58 \\
\hline & & & & No. 3 & 21 & 110.0 & 96.0 & 58 \\
\hline & & & & No. 4 & 21 & 109.3 & 93.9 & 58 \\
\hline CR & 16 & $F$ & 168 & & 35 & 104.1 & 88.4 & 66 \\
\hline ML & 26 & $F$ & 176 & & 40 & 147.3 & 124.2 & 131 \\
\hline MB & 43 & $\mathrm{~F}$ & 173 & & 41 & 123.5 & 98.8 & 98 \\
\hline $\mathrm{RM}$ & 52 & $\mathrm{~F}$ & 165 & & 42 & 88.2 & 72.0 & 45 \\
\hline \multirow[t]{2}{*}{ LM } & 24 & $\mathrm{~F}$ & 170 & No.1‡ & 21 & 99.1 & 87.9 & 48 \\
\hline & & & & No. 2 & 21 & 95.0 & 81.1 & 42 \\
\hline
\end{tabular}

* From Metropolitan Life Insurance Tables, 1959.

$\ddagger \mathrm{FN}$ and LM were studied during four and two periods of starvation, respectively.

\section{METHODS}

\section{Subjects}

Prolonged starvation group. Nine obese subjects were studied during 13 periods of starvation at the Clinical Center of the Peter Bent Brigham Hospital (Table I). Each had volunteered to undergo prolonged fasting after failure of various dietary regimens. They were informed of the nature, purpose, and possible risks involved in the starvation and catheterization procedures. Six of these subjects (FN, AB, FF, CR, ML, and MB) are described in a previous report (3) along with the screening tests employed on all the subjects. RM had a history of angina pectoris and angiographic evidence of coronary artery disease. She had one bout of angina before fasting was begun but had none thereafter.

Each period of starvation on all subjects was preceded by at least 3 days of a $2500 \mathrm{Cal}$ diet consisting of $300 \mathrm{~g}$ of carbohydrate, $100 \mathrm{~g}$ of protein, and $85 \mathrm{~g}$ of fat. Daily intake during starvation was restricted to $1500 \mathrm{ml}$ of water, 17 $\mathrm{mEq}$ of $\mathrm{NaCl}$ (sugar-free tablets), one multivitamin tablet (Theragran, E. R. Squibb \& Sons, New York) and intermittently, $17 \mathrm{mEq}$ of $\mathrm{KCl}$ (gelatin capsules). $\mathrm{LM}$ and FN also received $5 \mathrm{mg}$ of folic acid (Folvite, Lederle Laboratories, Pearl River, N. Y.) daily during fast No. 2 and fast No. 3, respectively. Between periods of starvation, LM and FN were maintained on a $1200-1500 \mathrm{Cal}$ intake for at least 2-3 wk.

Postabsorptive and briefly fasted group for hepatic vein studies. Eight patients were studied while undergoing elective cardiac catheterization for diagnostic purposes (Table II) to provide baseline data on splanchnic amino acid exchange in the postabsorptive state (five subjects) and after brief (36-48 hr) fasting (three subjects). None of the patients had a history or evidence of right heart failure or primary liver disease. Liver function was considered normal on the basis of serum direct and indirect bilirubin, alkaline phosphatase, glutamic-oxalacetic transaminase, and lactic dehydrogenase. The patients were informed of the research procedure to be performed (hepatic vein catheterization) in addition to the usual diagnostic studies and gave their voluntary consent.

\section{Blood and urine collection and analyses}

Heparinized blood for amino acid analysis was obtained from an antecubital vein without stasis from seven of the subjects undergoing prolonged starvation (Table I : FF, GS, FN (fast No. 2), CR, MB, LM (fast No. 1), and RM) on the day fasting was initiated (day 0 ) and after $3,5,10,14$, 21 , and (in all but LM) 35-40 days of starvation. During FN's third and fourth fasts and LM's second fast, specimens were taken on day 0 and day 21 only. Additional "baseline" samples to determine intraindividual variation in

TABLE II

Clinical Data on Postabsorptive and Briefly Fasted Subjects Undergoing Hepatic Vein Catheterization

\begin{tabular}{lccccl}
\hline Subject & Age & Sex & Height & Weight & \multicolumn{1}{c}{ Cardiac diagnosis } \\
\hline \multicolumn{5}{c}{ cm } & $k g$ \\
\multicolumn{5}{c}{ Postabsorptive state $(12-14$ hr fast) } \\
LW & 32 & M & 174 & 87 & Mild pulmonic stenosis \\
JG & 21 & M & 180 & 68 & Mitral incompetence \\
NN & 21 & F & 168 & 68 & Mitral stenosis \\
KM & 20 & F & 157 & 49 & Mitral stenosis \\
FL & 34 & F & 157 & 66 & Combined mitral lesion \\
Brief (36-48 hr) fast & & & \\
JR & 16 & M & 185 & 84 & Normal (late systolic murmur) \\
RM & 66 & M & 180 & 82 & Coronary artery disease \\
SM & 31 & F & 163 & 67 & Mitral stenosis \\
\hline
\end{tabular}


the fed state were obtained over a 2-4 month period of continuous hospitalization from FN and LM after an overnight fast and after at least 3 days on the high carbohydrate diet described above. All of the above samples were drawn between 8 and 9 a.m. to preclude the influence of diurnal variation (6). Simultaneous arterial and hepatic and/or renal venous specimens were obtained from six subjects catheterized after 38-42 days of starvation (Table I: FF, FN (fast No. 1), AB, MB, RM, and ML) and from eight subjects during diagnostic cardiac catheterization (Table II).

Immediately after collection, the blood was centrifuged, the plasma deproteinized with sulfosalicylic acid (7) and the filtrates stored at $-20^{\circ} \mathrm{C}$ until analysis. The catheterization samples from $\mathrm{AB}, \mathrm{ML}$, and $\mathrm{FN}$ were not deproteinized until just before analysis.

Urinary amino acid and creatinine excretions were studied in those subjects undergoing renal vein catheterization (Table VI). An aliquot was taken from a $24 \mathrm{hr}$ urine collection completed on the morning of catheterization ( 7 a.m.), and acidified by the method of Stein (8) before chromatographic analysis.

Individual free amino acids were determined by the automated ion-exchange chromatographic technique (9) on a Beckman model $120 \mathrm{C}$ amino acid analyzer (Beckman Instrument Co., Palo Alto, Calif.). Since glutamine and asparagine are not separated by this method and are not quantitatively recovered from the column due in part to conversion to glutamate (10), these amino acids are not reported. On the other hand, deproteinization with sulfosalicylic rather than picric acid eliminated the need for passage of the protein-free filtrates through a Dowex 2 anion-exchange resin thus permitting recovery of tryptophan (11). Aspartic acid was present in all samples in such low concentration that integration of its peak was not possible. In the catheterization samples not immediately deproteinized cystine was not recovered (10).

For glucose determination, whole blood was added to tubes containing oxalate-fluoride and analyzed in triplicate within several hours by the Technicon AutoAnalyzer ferricyanide procedure (12) (Technicon Corporation, Ardsley, N.Y.). Creatinine was measured in urine by the AutoAnalyzer technique and in plasma by the picric acid method (13).

Endogenous creatinine clearance $\left(\mathrm{C}_{\mathrm{cr}}\right)$ was calculated from the urinary excretion rate and the mean value of three plasma samples obtained during the course of the urine collection. The amino acid clearances are approximate values since the arterial samples were obtained $2-3 \mathrm{hr}$ after completion of the urine collections.

\section{Catheterization and blood flow}

The methods employed for venous and cardiac catheterization have been published elsewhere (4). Cardiac output was determined by the dye dilution technique after intravenous injection of $5 \mathrm{mg}$ of Indocyanine green. Hepatic blood flow was estimated by the Indocyanine green plasma disappearance method in which arterial and hepatic venous plasma

TABLE III

Intraindividual Variation in Plasma Amino Acid Concentration in Two Obese Subjects in the Postabsorptive State

\begin{tabular}{|c|c|c|c|c|c|c|c|c|c|}
\hline & \multicolumn{5}{|c|}{ FN } & \multicolumn{4}{|c|}{ LM } \\
\hline & \multicolumn{4}{|c|}{ Day* } & \multirow{2}{*}{$\begin{array}{c}\text { Coefficient } \\
\text { of } \\
\text { variationf }\end{array}$} & \multicolumn{3}{|c|}{ Day* } & \multirow{2}{*}{$\begin{array}{c}\text { Coefficient } \\
\text { of } \\
\text { variation } \ddagger\end{array}$} \\
\hline & 4 & 10 & 70 & 130 & & 4 & 13 & 50 & \\
\hline & \multicolumn{4}{|c|}{ umoles/liter } & $\%$ & \multicolumn{3}{|c|}{ umoles/liter } & $\%$ \\
\hline Taurine & 55 & 41 & 27 & 40 & 28 & 60 & 57 & 55 & 4 \\
\hline Threonine & 113 & 136 & 82 & 106 & 20 & 106 & 144 & 183 & 27 \\
\hline Serine & 113 & 110 & 74 & 108 & 18 & 96 & 134 & 116 & 17 \\
\hline Proline & 201 & 349 & 287 & 225 & 25 & 153 & 136 & 169 & 11 \\
\hline Citrulline & 25 & 36 & 38 & 24 & 24 & 32 & 38 & 38 & 10 \\
\hline Glycine & 159 & 166 & 158 & 166 & 3 & 189 & 218 & 229 & 10 \\
\hline Alanine & 386 & 420 & 362 & 390 & 6 & 327 & 357 & 437 & 15 \\
\hline$\alpha$-aminobutyrate & 21 & 19 & 14 & 24 & 21 & 19 & 28 & 20 & 22 \\
\hline Valine & 328 & 353 & 285 & 356 & 10 & 214 & 197 & 214 & 5 \\
\hline$\frac{1}{2}$ Cystine & 138 & 127 & 136 & 115 & 8 & 137 & 115 & 122 & 9 \\
\hline Methionine & 20 & 15 & 11 & 17 & 24 & 20 & 22 & 23 & 9 \\
\hline Isoleucine & 86 & 83 & 76 & 82 & 5 & 56 & 52 & 66 & 13 \\
\hline Leucine & 169 & 146 & 132 & 180 & 14 & 109 & 103 & 96 & 6 \\
\hline Tyrosine & 70 & 51 & 54 & 68 & 15 & 55 & 52 & 58 & 5 \\
\hline Phenylalanine & 56 & 48 & 41 & 53 & 13 & 51 & 50 & 50 & 1 \\
\hline Ornithine & 64 & 80 & 79 & 86 & 12 & 45 & 71 & 72 & 24 \\
\hline Lysine & 192 & 203 & 175 & 198 & 6 & 153 & 186 & 166 & 10 \\
\hline Histidine & 75 & 72 & 65 & 79 & 8 & 65 & 78 & 69 & 9 \\
\hline Tryptophan & 55 & 39 & 33 & 39 & 24 & 52 & 39 & 42 & 15 \\
\hline Arginine & 57 & 78 & 51 & 55 & 20 & 67 & 81 & 87 & 13 \\
\hline
\end{tabular}

* Days refer to duration of hospitalization. Each sample was obtained after at least 3 days of a constant, high carbohydrate diet (see Methods).

$\ddagger$ Coefficient of variation $=\mathrm{sD} /$ mean $\times 100(14)$. 
dye concentrations are determined at 3-min intervals for 21 min after intravenous administration of $0.5 \mathrm{mg} / \mathrm{kg}$ body weight of dye (14). Renal plasma flow was measured as the clearance of sodium para-aminohippurate ( $\mathrm{PAH})$ after induction of a water diuresis (15). Three timed urine samples were collected at $30 \mathrm{~min}$ intervals and blood specimens were drawn at the midpoint of the urine collection periods. Statistical analyses were performed according to Snedecor (16).

\section{RESULTS}

In Table III are presented the plasma amino acid levels in two obese subjects studied repeatedly in the postabsorptive state on a high carbohydrate diet. With the exception of taurine and threonine, the coefficient of variation was less than $25 \%$ and for the majority it was below $15 \%$. Of note is the fact that alanine and glycine which demonstrated the most marked alterations in concentration during starvation (see below), were among the least variable on repeated study in the fed state.

The changes observed in plasma amino acid concentration during starvation may be divided into four patterns.

Transient, early increase (Fig. 1). The branched chain amino acids (valine, leucine, isoleucine) and $\boldsymbol{\alpha}$-aminobutyrate and methionine showed an early increment, which with the exception of methionine reached its peak at 5 days. The secondary decline extended to levels significantly below baseline (day 0 ) in the case of valine, leucine, and isoleucine.
Delayed increase (Fig. 2). Glycine, threonine, and serine demontrated a delayed though progressive increase during the course of starvation. Serine differed from the others in reaching its peak value at 21 days. Interestingly, glycine and threonine showed an initial decline which in the case of the latter was statistically significant $(P<0.05)$.

Progressive or delayed decrease (Fig. 3). The most common pattern was either a progressive or delayed decrease in plasma amino acid levels so that after 5-6 wk of fasting, 13 of the 20 amino acids measured were significantly lower than at the time starvation was initiated. Of special interest is the fact that both the absolute and relative decline in plasma alanine exceeded that of all other amino acids. In addition, the rate of decline in plasma alanine was most rapid during the 1st 5-10 days of starvation (Fig. 3).

No change. Only lysine and taurine failed to demonstrate any significant changes from the postabsorptive state.

The reproducibility of the plasma amino acid response to starvation was studied in FN and LM who underwent more than one fast. In both subjects the intraindividual variation in plasma concentration after 21 days of starvation was less than $15 \%$ of the mean value for each amino acid except threonine, proline, $\frac{1}{2}$ cystine, and ornithine. The latter group varied by $18-25 \%$. Although supplemental folic acid was given during one of

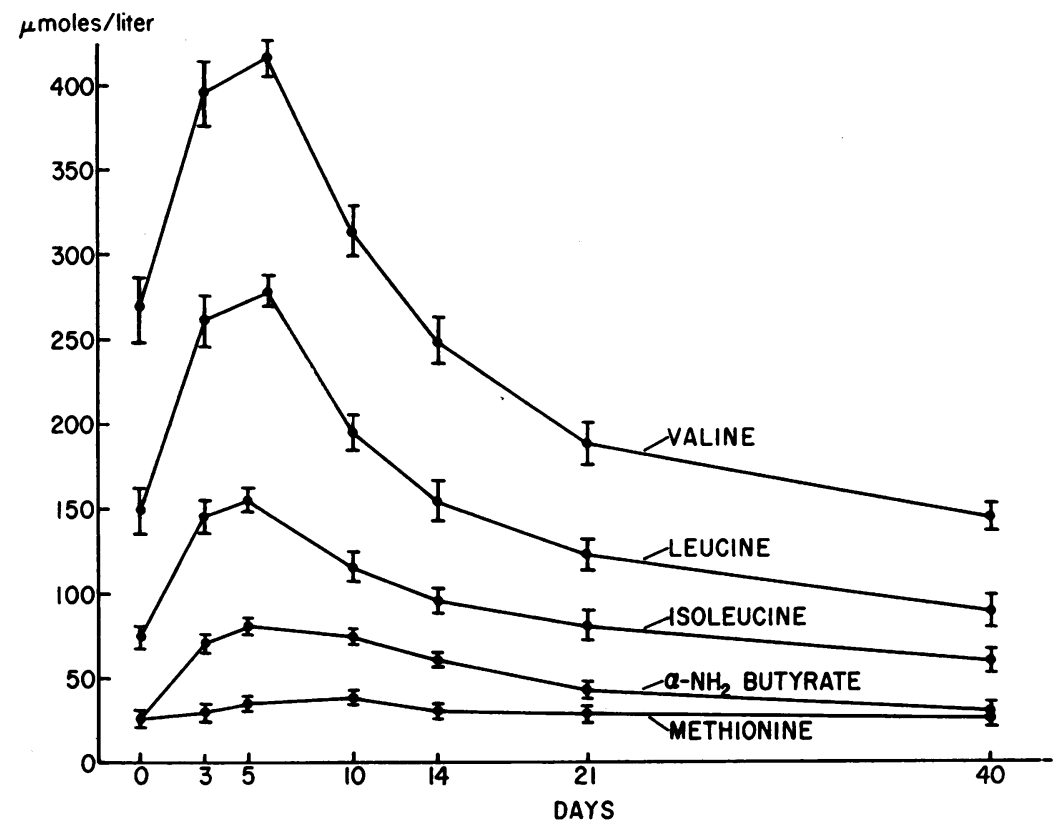

Figure 1 Plasma concentration of amino acids demonstrating a transient early increase in starvation. Seven obese subjects were studied during prolonged fasting at the intervals indicated. Values in this and the following two figures represent the mean $\pm S E$. 


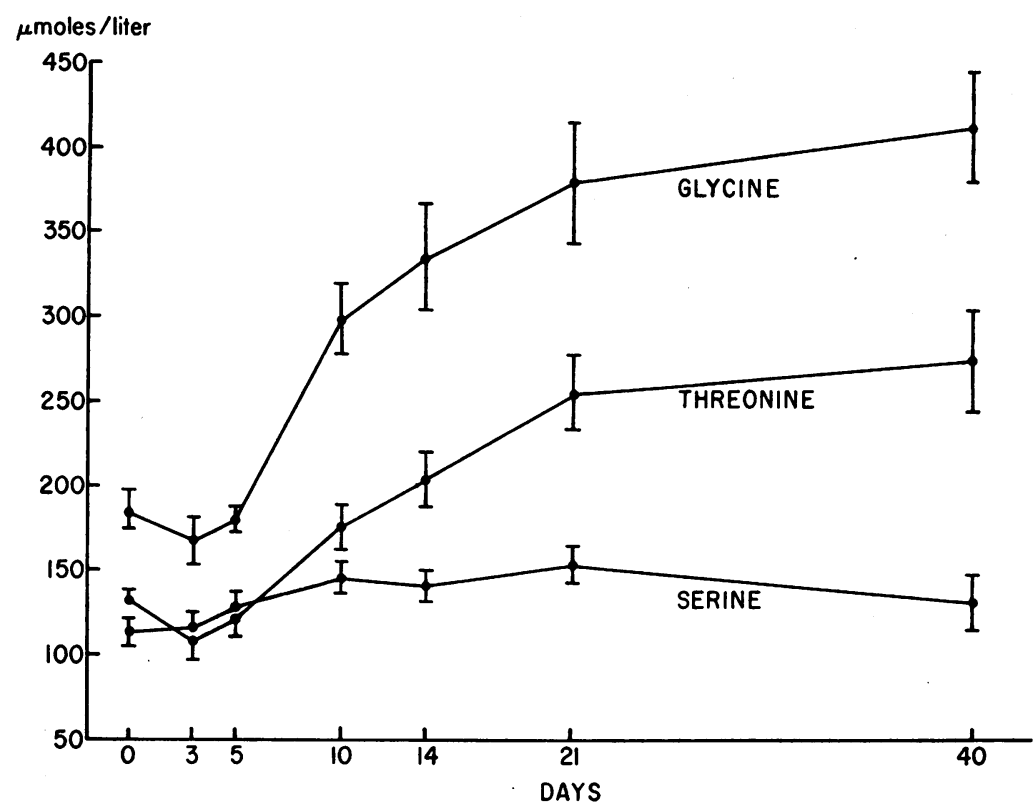

FIGURE 2 Plasma concentration of those amino acids demonstrating a delayed increase in starvation. The early fall in threonine was statistically significant.

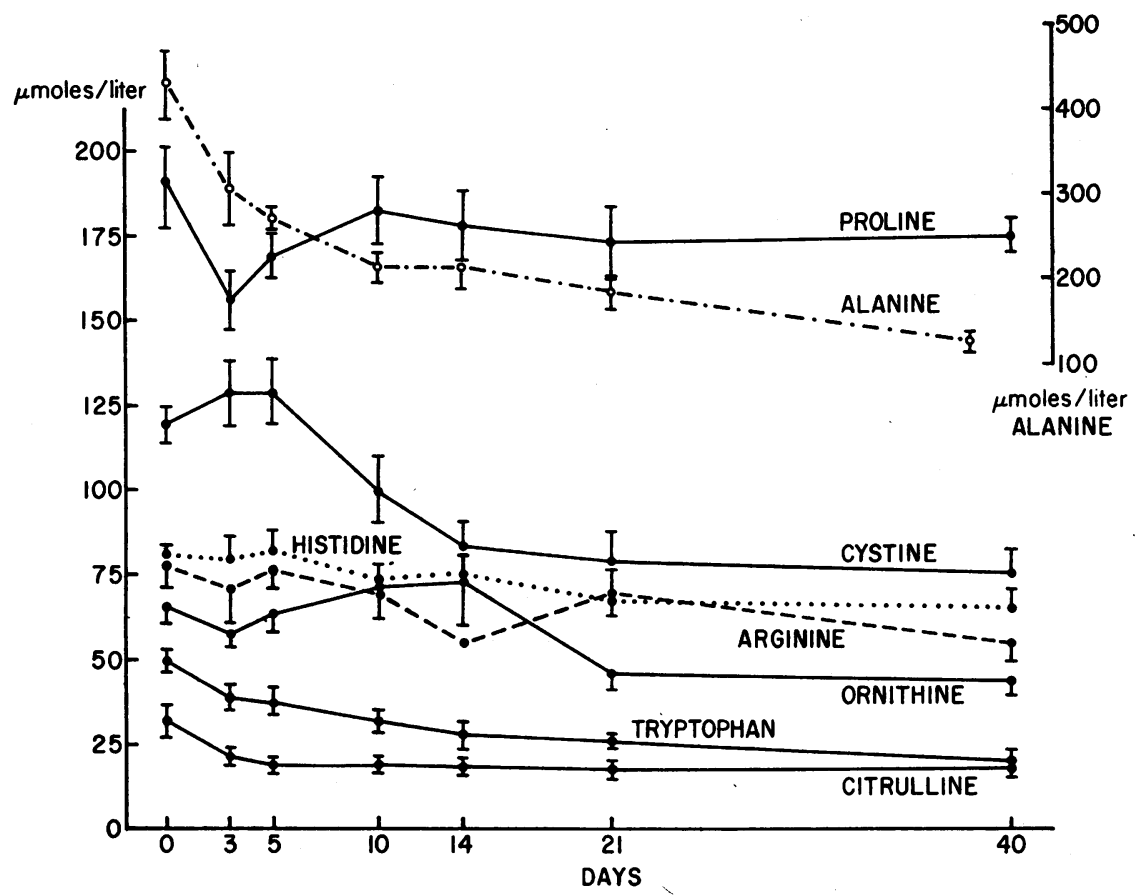

FIGURE 3 Plasma concentration of those amino acids which fell below baseline levels (day 0 ) during the course of prolonged fasting. Valine, isoleucine, and leucine which ultimately decreased are presented in Fig. 1. Tyrosine and phenylalanine which did not change significantly until day 40 are not shown here. Note the separate scale for alanine. 


\section{TABLE IV}

Hemodynamic Data and Net Splanchnic Glucose Output in Subjects Studied by Hepatic Venous Catheterization

\begin{tabular}{|c|c|c|c|c|}
\hline Subject & $\begin{array}{l}\text { Cardiac } \\
\text { output }\end{array}$ & $\mathrm{HBF}^{*}$ & $\begin{array}{c}\text { Arterial } \\
\text { Hct }\end{array}$ & $\begin{array}{c}\text { Glucose } \\
\text { A-HV }\end{array}$ \\
\hline & liters/min & liters/min & $\%$ & $m g \%$ \\
\hline \multicolumn{5}{|c|}{ Postabsorptive (12-14 hr fast) } \\
\hline LW & 5.0 & 1.47 & 42 & 17 \\
\hline JG & 4.0 & - & 46 & 19 \\
\hline NN & 5.9 & - & 38 & 10 \\
\hline $\mathbf{K} \mathbf{M}$ & 4.3 & 0.99 & 43 & 9 \\
\hline FL & 3.4 & - & 37 & 9 \\
\hline
\end{tabular}

Brief $(36-48 \mathrm{hr})$ fast

\begin{tabular}{|c|c|c|c|c|}
\hline $\mathrm{JR}$ & 5.4 & - & 47 & 10 \\
\hline RM & 4.5 & - & 42 & 9 \\
\hline $\mathrm{SM}$ & 3.1 & - & 44 & 6 \\
\hline \multicolumn{5}{|c|}{ Prolonged (5-6 wk) fast $\S$} \\
\hline MB & 4.5 & 1.13 & 33 & 3 \\
\hline FF & 4.7 & 1.25 & 39 & 3 \\
\hline $\mathbf{R M}$ & - & - & 38 & 3 \\
\hline FN & 4.2 & - & 42 & 5 \\
\hline
\end{tabular}

* Hepatic blood flow.

¥ Arterio-hepatic venous differences. Values are means of two sets of simultaneous samples in the postabsorptive and briefly fasted groups and of four sets in the prolonged starvation group.

$\S$ Data on MB, FF, and FN have been reported previously (3).

the fasts to both FN and LM, it failed to prevent the increase in plasma glycine (see Discussion).

The hemodynamic data and splanchnic glucose outputs of the patients undergoing hepatic vein catheterization are presented in Table IV. The arterial levels and the net splanchnic exchange of amino acids are shown in Table V. Although the levels of most amino acids were lower in hepatic venous than in arterial blood, alanine was taken up to a much greater extent than all other amino acids in all subjects. A consistent output was demonstrated only for citrulline.

After a brief fast (36-48 hr) the general pattern of amino acid exchange was similar to the postabsorptive state. However, there was a marked increase in the A-V difference for alanine which in the absence of any significant change in the arterial alanine level was attributable to the increment in fractional extraction of this amino acid from 43 to $71 \%$ (Fig. 4). While one cannot exclude the possibility of a decrease in hepatic blood flow to account for the change in $\mathrm{A}-\mathrm{V}$ difference, this seems unlikely inasmuch as cardiac output did not differ significantly in the two groups (Table VI).

After prolonged fasting, alanine remained the prime amino acid taken up by the liver; however there was a marked falloff in the $\mathrm{A}-\mathrm{V}$ difference for this amino acid. With respect to the findings in the postabsorptive state, this diminution was due to the decline in arterial alanine levels since the mean fractional alanine extraction did not differ significantly between these two groups (Fig. 4). On the other hand, alterations in both the arterial levels and extraction ratios contributed to the decline in alanine uptake when compared to the briefly fasted subjects (Fig. 4). The net splanchnic exchange of the remainder of the amino acids was not significantly

TABLE V

Arterial Concentrations and Arterio-Hepatic Venous Differences ( $A-H V$ ) of Plasma Amino Acids in the Postabsorptive State and After Brief (36-48 hr) and Prolonged (5-6 wh) Starvation

\begin{tabular}{|c|c|c|c|c|c|c|c|c|c|}
\hline & \multicolumn{3}{|c|}{ Postabsorptive $(\mathrm{N}=5)$} & \multicolumn{3}{|c|}{ Brief fast $(\mathrm{N}=3)$} & \multicolumn{3}{|c|}{ Prolonged fast $(\mathrm{N}=4)$} \\
\hline & Arterial level & A-HV & $P^{*}$ & Arterial level & A-HV & $P^{*}$ & Arterial level & A-HV & $P^{*}$ \\
\hline Taurine & $50.4 \pm 1.9 \ddagger$ & $2.1 \pm 1.0$ & ns & $66.8 \pm 1.6$ & $2.1 \pm 2.8$ & ns & $52.2 \pm 1.2$ & $0.1 \pm 0.1$ & ns \\
\hline Threonine & $144.3 \pm 13.1$ & $24.3 \pm 7.8$ & $<0.025$ & $121.0 \pm 16.1$ & $42.3 \pm 15.1$ & $\mathrm{~ns}$ & $224.1 \pm 15.9$ & $14.7 \pm 5.4$ & $<0.05$ \\
\hline Serine & $128.8 \pm 8.7$ & $31.5 \pm 8.3$ & $<0.01$ & $113.5 \pm 6.5$ & $43.3 \pm 8.1$ & $<0.025$ & $110.7 \pm 10.2$ & $25.9 \pm 3.0$ & $<0.005$ \\
\hline Proline & $191.1 \pm 2.9$ & $17.5 \pm 10.4$ & ns & $230.1 \pm 22.7$ & $48.2 \pm 24.2$ & ns & $176.5 \pm 11.1$ & $8.1 \pm 4.3$ & ns \\
\hline Citrulline & $29.7 \pm 3.2$ & $-9.1 \pm 2.8$ & $<0.025$ & $27.9 \pm 6.4$ & $-0.5 \pm 4.2$ & $\mathrm{~ns}$ & $15.7 \pm 3.3$ & $-5.9 \pm 2.4$ & $<0.01$ \\
\hline Glycine & $263.6 \pm 43.3$ & $40.9 \pm 10.6$ & $<0.01$ & $188.7 \pm 17.7$ & $68.0 \pm 20.9$ & $<0.05$ & $361.8 \pm 22.2$ & $7.6 \pm 9.8$ & ns \\
\hline Alanine & $292.8 \pm 28.8$ & $120.6 \pm 15.7$ & $<0.005$ & $321.3 \pm 37.5$ & $232.3 \pm 38.6$ & $<0.025$ & $111.0 \pm 12.9$ & $59.5 \pm 11.5$ & $<0.01$ \\
\hline$\alpha$-aminobutyrate & $19.3 \pm 4.9$ & $2.6 \pm 1.3$ & ns & $33.4 \pm 13.5$ & $6.7 \pm 3.5$ & ns & $26.2 \pm 1.2$ & $2.5 \pm 1.7$ & ns \\
\hline Valine & $204.9 \pm 24.2$ & $13.5 \pm 5.5$ & $<0.05$ & $264.9 \pm 40.6$ & $43.5 \pm 31.2$ & ns & $129.1 \pm 6.9$ & $9.7 \pm 6.2$ & ns \\
\hline Cystine & $101.9 \pm 4.5$ & $3.1 \pm 2.9$ & ns & $110.1 \pm 14.6$ & $25.2 \pm 11.6$ & ns & $86.7 \pm 6.1$ & $10.2 \pm 3.2$ & ns \\
\hline Methionine & $23.1 \pm 1.5$ & $4.5 \pm 2.2$ & $\mathrm{~ns}$ & $20.9 \pm 2.9$ & $10.2 \pm 1.8$ & $<0.025$ & $18.4 \pm 4.0$ & $5.2 \pm 8.9$ & $<0.01$ \\
\hline Isoleucine & $55.7 \pm 7.2$ & $4.6 \pm 4.0$ & ns & $77.6 \pm 14.0$ & $9.1 \pm 8.1$ & ns & $58.6 \pm 5.2$ & $6.0 \pm 3.1$ & ns \\
\hline Leucine & $108.9 \pm 16.7$ & $9.0 \pm 8.4$ & ns & $151.6 \pm 29.2$ & $38.4 \pm 14.3$ & ns & $77.9 \pm 4.6$ & $15.9 \pm 2.8$ & $<0.01$ \\
\hline Tryosine & $47.0 \pm 3.3$ & $12.3 \pm 1.5$ & $<0.005$ & $57.0 \pm 4.0$ & $15.2 \pm 3.3$ & $<0.025$ & $56.8 \pm 4.0$ & $10.4 \pm 1.8$ & $<0.005$ \\
\hline Phenylalanine & $47.0 \pm 3.0$ & $9.4 \pm 2.4$ & $<0.01$ & $44.7 \pm 8.0$ & $12.1 \pm 5.2$ & ns & $39.1 \pm 2.5$ & $8.4 \pm 1.0$ & $<0.005$ \\
\hline Ornithine & $72.4 \pm 9.0$ & $-8.1 \pm 8.4$ & ns & $59.9 \pm 7.4$ & $6.2 \pm 3.0$ & $\mathrm{~ns}$ & $37.2 \pm 4.7$ & $1.0 \pm 3.3$ & ns \\
\hline Lysine & $179.6 \pm 12.0$ & $-0.2 \pm 8.6$ & ns & $154.5 \pm 7.6$ & $36.2 \pm 11.8$ & $<0.05$ & $180.5 \pm 30.5$ & $20.0 \pm 7.6$ & $<0.05$ \\
\hline Histidine & $75.9 \pm 4.4$ & $4.6 \pm 4.2$ & ns & $89.0 \pm 10.8$ & $16.7 \pm 7.9$ & ns & $53.1 \pm 8.6$ & $4.2 \pm 2.5$ & ns \\
\hline Tryptophan & $40.8 \pm 4.4$ & $-9.8 \pm 1.3$ & ns & $31.4 \pm 2.0$ & $-1.9 \pm 2.8$ & ns & $21.7 \pm 8.7$ & $-5.4 \pm 2.1$ & ns \\
\hline Arginine & $67.3 \pm 10: 1$ & $5.8 \pm 6.2$ & ns & $46.9 \pm 4.2$ & $13.3 \pm 3.8$ & $<0.05$ & $63.5 \pm 10.8$ & $6.0 \pm 4.7$ & ns \\
\hline
\end{tabular}

$* P=$ probability that A-HV does not differ from zero (paired $t$ test).

$\ddagger$ Mean \pm SE, $\mu$ moles/liter. 


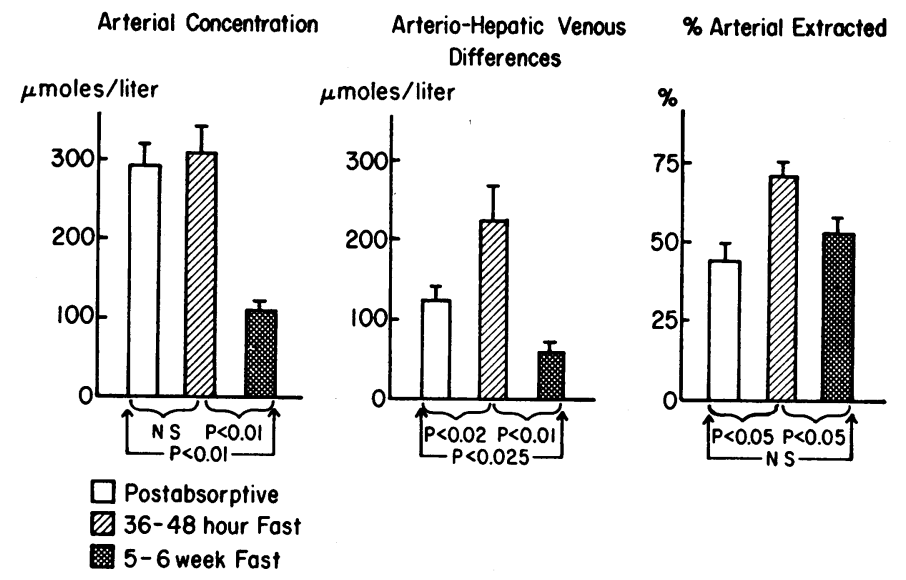

FIGURE 4 Arterial concentration and splanchnic extraction of plasma alanine in five postabsorptive subjects (open bars), and in three subjects fasted 36-48 hr (cross-hatched bars), and four subjects fasted 5-6 wk (shaded bars). Lines at top of bars represent standard error. $P$ values are based on $t$ test.

TABLE VI

Arterial Plasma Concentration, Arterio-Renal Venous Differences ( $A-R V)$, Urinary Excretion, and Renal Clearances of Free Amino Acids in Four Obese Subjects after 5-6 wk of Starvation

\begin{tabular}{|c|c|c|c|c|c|}
\hline & $\begin{array}{l}\text { Arterial con- } \\
\text { centration }\end{array}$ & $A-R V$ & $P \ddagger$ & $\begin{array}{c}\text { Urinary } \\
\text { excretion§ }\end{array}$ & $\begin{array}{c}\text { Renal } \\
\text { clearance }\end{array}$ \\
\hline & umoles/liter & umoles/liter & & $\mu m o l e s / 24 h r \S$ & $\mathrm{ml} / \mathrm{min}$ \\
\hline Taurine & $55.6 \pm 4.4$ & $6.9 \pm 3.7$ & NS & $419 \pm 241$ & $5.3 \pm 3.1$ \\
\hline Threonine & $179.0 \pm 34.4$ & $-5.2 \pm 4.8$ & NS & $265 \pm 70$ & $1.0 \pm 0.2$ \\
\hline Serine & $130.5 \pm 10.9$ & $-36.0 \pm 2.9$ & $<0.005$ & $364 \pm 48$ & $1.9 \pm 0.2$ \\
\hline Proline & $155.8 \pm 11.7$ & $13.0 \pm 2.3$ & $<0.01$ & Trace-37 & up to 0.2 \\
\hline Citrulline & $13.0 \pm 1.3$ & $3.0 \pm 1.6$ & NS & $15 \pm 5$ & $0.8 \pm 0.2$ \\
\hline Glycine & $337.0 \pm 20.7$ & $37.5 \pm 5.6$ & $<0.005$ & $1843 \pm 405$ & $4.2 \pm 1.1$ \\
\hline Alanine & $112.3 \pm 14.3$ & $9.3 \pm 3.8$ & $<0.05$ & $74 \pm 12$ & $0.5 \pm 0.1$ \\
\hline$\alpha$-aminobutyrate & $32.5 \pm 6.5$ & $2.0 \pm 1.3$ & NS & $18 \pm 2$ & $0.4 \pm 0.1$ \\
\hline Valine & $186.5 \pm 60.4$ & $-0.5 \pm 4.0$ & NS & $53 \pm 12$ & $0.3 \pm 0.1$ \\
\hline$\frac{1}{2}$ Cystine $\|$ & 80.6 & -8.0 & - & $131 \pm 54$ & 1.22 \\
\hline Methionine & $15.7 \pm 4.8$ & $-4.5 \pm 1.0$ & NS & $8 \pm 2$ & $0.5 \pm 0.3$ \\
\hline Isoleucine & $59.6 \pm 6.5$ & $-3.6 \pm 2.4$ & NS & $48 \pm 8$ & $0.5 \pm 0.1$ \\
\hline Leucine & $75.2 \pm 4.2$ & $-6.5 \pm 6.3$ & NS & $52 \pm 4$ & $0.4 \pm 0.01$ \\
\hline Tyrosine & $44.7 \pm 9.0$ & $-5.2 \pm 2.2$ & NS & $55 \pm 7$ & $1.0 \pm 0.1$ \\
\hline Phenylalanine & $34.1 \pm 3.0$ & $0.8 \pm 1.9$ & NS & $27 \pm 4$ & $0.6 \pm 0.1$ \\
\hline Ornithine & $31.4 \pm 1.9$ & $-2.6 \pm 3.4$ & NS & - & - \\
\hline Lysine & $125.4 \pm 6.6$ & $-5.7 \pm 9.8$ & NS & - & - \\
\hline Histidine & $43.5 \pm 2.8$ & $-0.3 \pm 2.5$ & NS & - & - \\
\hline Tryptophan & $18.6 \pm 6.5$ & $-9.2 \pm 9.3$ & NS & - & - \\
\hline Arginine & $47.9 \pm 4.0$ & $-2.9 \pm 5.9$ & NS & - & - \\
\hline
\end{tabular}

* $\mathrm{C}_{\mathrm{PAH}}=691 \pm 101$, and $\mathrm{C}_{\mathrm{cr}}=79 \pm 6(\mathrm{ml} / \mathrm{min}$, mean $\pm \mathrm{SE})$ for the four subjects.

$\ddagger P=$ probability that A-RV does not differ from zero (paired $t$ test).

\$ Urinary excretion rates of basic amino acids were not measured.

\| Cystine was measured in arterial and venous plasma of MB only (see Methods).

All other values are mean $\pm \mathrm{SE}$. 
altered by prolonged fasting, with the striking exception of glycine. Although the hepatic A-V difference for this amino acid was second to that of alanine in the postabsorptive and briefly fasted subjects, there was no significant uptake at 40 days of starvation despite an increase in plasma glycine concentration.

The creatinine and para-aminohippurate clearances ( $\mathrm{C}_{\mathrm{cr}}$ and $\mathrm{C}_{\mathrm{PAH}}$, respectively) of the subjects studied by renal vein catheterization, and the mean arterial levels, arterio-renal venous differences, urinary excretion rates, and renal clearances for all of the amino acids are presented in Table VI. All patients showed a net renal uptake of glycine, proline, and alanine and a net release of serine. For the remainder of the amino acids studied, the renal exchange was either too small or variable to result in statistically significant arterio-renal venous differences. The urinary excretion of glycine was much greater than that of all other amino acids, reflecting both its increased arterial concentration and its relatively high clearance rate.

\section{DISCUSSION}

In a previous study from this laboratory (3), a decrease in total serum amino acids was observed during starvation. However, neither the early increment in branched chain amino acids, the late rise in glycine, nor the magnitude of the fall in alanine could be detected from the changes noted in total alpha amino nitrogen. Whereas alanine decreased by $70 \%$, total alpha amino nitrogen fell only $12 \%$ (3). The multidirectional pattern of the response of individual amino acids to starvation is thus masked by any determination in which the entire group is measured as a single entity. Similarly, reports lumping amino acids into essential and nonessential groups and emphasizing the ratio between these groups during starvation (17) fail to consider the divergent response of alanine and glycine, both of which are nonessential. On the other hand, in an independent study in which individual plasma amino acids were measured in subjects fasted $2 \mathrm{wk}$, Adibi (18) recently reported findings virtually identical with the current data. Furthermore, Adibi's observation that the plasma amino acid pattern in starvation was the same for both obese and nonobese subjects (18) lends further support to the thesis advanced elsewhere (4) that these two groups behave similarly in their metabolic adaptation to starvation.

The transient increment in specific amino acids early in starvation is of interest in that this elevation coincides with the period of maximal fall in serum insulin (3). That insulin lowers plasma amino acid levels has been known for many years (19), and more recent studies have demonstrated a direct in vivo inhibition of peripheral amino acid release from resting muscle
(20). In addition, an elevation in branched chain amino acids has been observed in diabetics (21) and in pancreatectomized dogs (22). Furthermore, the branched chain amino acids as well as alpha aminobutyrate and methionine are among the amino acids most sensitive tc altered systemic insulin levels $(23,24)$. Thus the hyperaminoacidemia of early starvation may reflect an insulinmodulated augmentation of release from peripheral protein stores. However, the possibility of altered hepatic exchange must also be considered in view of in vitro evidence of preferential release of branched chain amino acids by perfused rat liver (25).

Although the majority of plasma amino acids ultimately decrease in starvation, the magnitude of this decline in both absolute and relative terms is greatest for alanine. Some understanding of the mechanism and significance of this diminution is provided by the data obtained by simultaneous arterial and hepatic vein catheterization. It is recognized that this technique determines total splanchnic exchange and does not permit identification of the relative contributions of hepatic and nonhepatic tissues to the observed arterio-hepatic venous differences. However, studies in fasted animals have demonstrated portal vein alanine levels (26) in the same range as in arterial plasma (27) and an equivalence of essential amino acid concentrations in portal and radial venous blood $(28,29)$. Thus it is unlikely that the splanchnic uptake of alanine noted in the present study is due to extrahepatic extraction or that significant amounts of alanine are released by the tissues drained by the portal vein in postabsorptive or fasted subjects. Furthermore, the demonstration of a consistent splanchnic output only for citrulline, a urea cycle intermediate not found in protein and synthesized almost exclusively in the liver (30), suggests that nonhepatic tissues contribute little to the over-all amino acid balance.

In the only previous study in humans on splanchnic amino acid exchange, Carlsten et al. (5) noted that uptake of alanine greatly exceeded that of all other amino acids. Though no data on hepatic blood flow or cardiac output are provided, their observation of a mean $A-V$ difference for alanine of $103 \pm 27 \mu$ moles/liter in three normal controls, agrees well with the value of $121 \pm 16$ demonstrated in the postabsorptive subjects in the present study. The primacy of alanine in the flow of amino acids from the periphery to the liver is underscored by the observation that alanine output from resting muscle exceeds that of all other amino acids $(20,31)$ and that hepatic rates of gluconeogenesis from alanine are among the highest reported for any amino acid (32). In addition, the augmentation in alanine extraction demonstrated after a brief fast $(36-48 \mathrm{hr})$ is consistent with the marked increase in activity of key gluconeogenic enzymes observed in rats after similar periods of starvation $(33,34)$. 
The available evidence thus points to preferential and initially augmented splanchnic utilizatioon of alanine resulting ultimately in substrate depletion as the mechanism responsible for the diminution in plasma concentration. Significantly, Williamson, Lopes-Vieira, and Walker (35) have demonstrated that hepatic levels of free alanine are decreased to a greater extent than other gluconeogenic amino acids in rats after $48 \mathrm{hr}$ of starvation. In addition, an inverse relation between tissue alanine levels and alterations in gluconeogenic rates produced by diverse influences has recently been observed (36).

The significance of the reduced plasma alanine levels in prolonged fasting is apparent from the hepatic vein studies performed after 5-6 wk of starvation. Although the fractional extraction of alanine is slightly (though not significantly) greater than the postabsorptive levels, the $\mathrm{A}-\mathrm{V}$ difference is reduced by half. Clearly the most important factor determining net splanchnic alanine uptake in prolonged fasting is the arterial concentration. The data thus suggest that maintenance of hypoalaninemia, presumably via diminution in alanine release from the periphery, is a crucial step in the regulatory mechanism minimizing protein conversion to carbohydrate in prolonged fasting. In accord with this hypothesis is the observation that when plasma alanine concentration is raised in starvation by intravenous infusion of this amino acid, a prompt hyperglycemic response is noted. ${ }^{1}$

In contrast to the behavior of all other amino acids, the plasma concentration of glycine, threonine, and to a lesser extent serine, showed a delayed increase in starvation. A similarly anomalous response has been noted for glycine in protein-calorie malnutrition (37). Inasmuch as threonine is essential and can be converted to glycine, a block in the metabolism of the latter could lead to accumulation of both. In this regard, the possibility of folate deficiency was considered since glycine is unique in its requirement of folic acid for gluconeogenesis (38). However, administration of folate supplements to two subjects was without effect in preventing the late increase in plasma glycine and threonine. In addition, though the decrease in splanchnic glycine uptake to insignificant levels after prolonged fasting suggests underutilization, its importance in over-all glycine balance is mitigated by the high rate of renal extraction which is far in excess of that noted in postabsorptive subjects (see below). Thus the accumulation of glycine and threonine in plasma is probably due to increased peripheral release.

The exchange of amino acids across the kidney was investigated in view of the significant rates of renal

\footnotetext{
${ }^{1}$ Felig, P., O. E. Owen, and G. F. Cahill, Jr. Data in preparation.
}

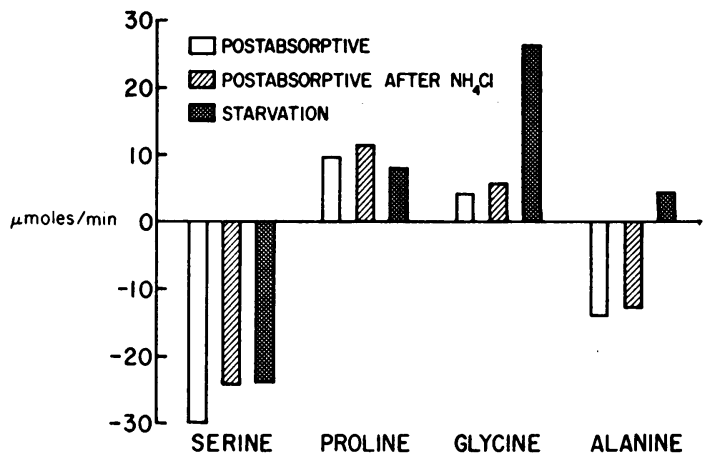

FIgure 5 Net renal exchange of selected amino acids in postabsorptive subjects with and without pretreatment with ammonium chloride [data of Owen and Robinson (40)], and in subjects fasted 5-6 wk. Only those amino acids for which a statistically significant arterio-renal venous difference (A-RV) was demonstrated (Table VI) are shown. Net exchange was calculated from A-RV and $C_{P A H}$ (Table VI).

gluconeogenesis observed in prolonged fasting (3). Previous studies have emphasized the importance of glutamine in total nitrogen balance and ammonia production by the kidney (39). Though no data are presented regarding this amino acid, it is interesting to compare the net renal exchange of those amino acids for which significant $\mathrm{A}-\mathrm{V}$ differences were demonstrated in starvation with the values reported in postabsorptive subjects (40). As shown in Fig. 5, the uptake of proline and release of serine are virtually equal to those seen in the nonfasted state. However, the extraction of glycine is increased 4- to 6-fold, while there is a directional change in alanine, from release to a net uptake in starvation. When the urinary excretion rates of these amino acids (Table VI) are included in the calculations to determine total balance across the kidney, the extraction rates are not significantly affected. Although the level of urinary ammonia excretion in starvation (3) is comparable to that of subjects administered ammonium chloride (40), it is clear from Fig. 5 that increased ammonia excretion per se is not responsible for the altered amino acid exchanges observed in prolonged fasting.

The increase in renal glycine uptake in association with an elevated arterial concentration is consistent with the data of Pitts and Pilkington (41) on glycine incorporation into urinary ammonia. However, inasmuch as uptake rose to a much greater extent than arterial concentration, a primary stimulation of glycine uptake is likely. Even more striking is the demonstration of a net renal extraction of alanine in the face of markedly reduced arterial levels. Since previous studies have revealed that the kidney both synthesizes and metabolizes alanine with net exchange depending on substrate availability (42), it is likely that the net extraction of alanine in starvation is consequent to a siphoning off 
of this amino acid and of its precursor, pyruvate, for gluconeogenesis (3).

\section{ACKNOWLEDGMENTS}

We wish to express our appreciation to Miss Judith Flewelling and to Mrs. Dzidra Rumba, Adacie Allen, Velta Ramolins, and Anna Karras for their technical assistance, to Dr. Ray Gleason for helpful suggestions regarding the statistical analyses, and to the nurses and staff of the Clinical Center and Cardiovascular Research Unit at the Peter Bent Brigham Hospital.

This work was supported in part by U. S. Public Health Service Grants AM-05077, AM-09584, AM-09748, HE05679, HE-08591, HE-11306, and FR-31, and the John $\mathrm{H}$. Hartford Foundation, Inc., New York.

\section{REFERENCES}

1. Felig, P., O. E. Owen, and G. F. Cahill, Jr. 1968. Role of plasma amino acids in the regulation of gluconeogenesis. J. Clin. Invest. 47: 32 (Abstr.)

2. Cahill, G. F., Jr., M. G. Herrera, A. P. Morgan, J. S. Soeldner, J. Steinke, P. L. Levy, G. A. Reichard, Jr., and D. M. Kipnis. 1966. Hormone-fuel interrelationships during fasting. J. Clin. Invest. 45: 1751.

3. Owen, O. E., P. Felig, A. P. Morgan, J. Wahren, and G. F. Cahill, Jr. Liver and kidney metabolism during prolonged starvation. J. Clin. Invest. 48: 574.

4. Owen, O. E., A. P. Morgan, H. G. Kemp, J. M. Sullivan, M. G. Herrera, and G. F. Cahill, Jr. 1967. Brain metabolism during fasting. J. Clin. Invest. 46: 1589.

5. Carlsten, A., B. Hallgren, R. Jagenburg, A. Svanborg, and L. Werkö. 1967. Arteriohepatic venous differences of free fatty acids and amino acids. Acta Med. Scand. $181: 199$.

6. Feigen, R. D., A. S. Klainer, and W. R. Beisel. 1967. Circadian periodicity of blood amino-acids in adult man. Nature (London). 215: 512.

7. Block, W. D., M. E. Markovs, and B. F. Steele. 1966. Comparison between free amino acid levels in plasma deproteinated with picric acid and with sulfosalicylic acid. Proc. Soc. Exp. Biol. Med. 122: 1089.

8. Stein, W. H. 1953. A chromatographic investigation of of the amino acid constituents of normal urine. J. Biol. Chem. 201: 45.

9. Spackman, D. H., W. H. Stein, and S. Moore. 1958. Automatic recording apparatus for use in the chromatography of amino acids. Anal. Chem. 30: 1185 .

10. Stein, W. H., and S. Moore. 1954. The free amino acids of human blood plasma. J. Biol. Chem. 211: 915.

11. Dickinson, J. C., H. Rosenblum, and P. B. Hamilton. 1965. Ion exchange chromatography of the free amino acids in the plasma of the newborn infants. Pediatrics. $36: 2$.

12. Hoffman, W. S. 1937. A rapid photoelectric method for the determination of glucose in blood and urine. J. Biol. Chem. 120: 51 .

13. Bonsnes, R. W., and H. H. Taussky. 1945. On the colorimetric determination of creatinine by the Jaffe reaction. J. Biol. Chem. 158: 581.

14. Caesar, J., S. Shaldon, L. Chiandussi, L. Guevara, and S. Sherlock. 1961. The use of indocyanine green in the measurement of hepatic blood flow and as a test of hepatic function. Clin. Sci. 21: 43 .
15. Smith, H. W. 1956. Principles of Renal Physiology. Oxford University Press, New York. 200.

16. Snedecor, G. W. 1956. Statistical Methods, Iowa State College Press, Ames. 5th edition. 35.

17. Drenick, E. J., M. E. Swendseid, W. H. Blahd, and S. G. Tuttle. 1964. Prolonged starvation as treatment of severe obesity. J. Amer. Med. Ass. 187: 100.

18. Adibi, S. A. 1968. Influence of dietary deprivations on plasma concentration of free amino acids in man. J. Appl. Physiol. 25: 52.

19. Luck, J. M., G. Morrison, and L. F. Wilbur. 1928. The effect of insulin on the amino acid content of blood. J. Biol. Chem. 77: 151.

20. Pozefsky, T., P. Felig, J. S. Soeldner, and G. F. Cahill, Jr. Insulin blockade of amino acid release by human forearm tissues. Trans. Ass. Amer. Physicians Philadelphia. In press.

21. Carlsten, A., B. Hallgren, R. Jagenburg, A. Svanborg, and L. Werkö. 1966. Amino acids and free fatty acids in plasma in diabetes. I. The effect of insulin on arterial levels. Acta Med. Scand. 179: 361

22. Ivy, J. H., M. Svec, and S. Freeman. 1951. Free plasma levels and urinary excretion of eighteen amino acids in normal and diabetic dogs. Amer. J. Physiol. 167: 182.

23. Zieneman, H. H., F. A. Nuttall, and F. C. Goetz. 166. Effect of endogenous insulin on human amino acid metabolism. Diabetes. 15: 5 .

24. De Barnola, F. V. 1965. The effect of insulin on plasma free amino acids. Acta Physiol. Latinoamer. 15: 260.

25. Schimassek, H., and W. Gerok. 1965. Control of the levels of free amino acids in plasma by the liver. Biochem. Z. 343: 407.

26. Wheeler, P., and A. F. Morgan. 1958. The absorption by immature and adult rats of amino acids from raw and autoclaved fresh pork. J. Nutr. 64: 137.

27. Scharrf, R., and I. G. Wool. 1964. Concentration of amino acids in rat muscle and plasma. Nature (London). 202: 603 .

28. Denton, A. E., S. N. Gershoff, and C. A. Elvehjem. 1953. A new method for cannulating the portal vein of dogs. J. Biol. Chem. 204: 731.

29. Denton, A. E., and C. A. Elvehjem. 1954. Availability of amino acids in vivo. J. Biol. Chem. 206: 449.

30. McMurray, W. C., J. C. Rothbun, F. Mohyuddin, and S. J. Koegler. 1963. Citrullinuria. Pediatrics. 32: 347.

31. London, D. R., T. H. Foley, and C. G. Webb. 1965. Evidence for the release of individual amino acids from the resting human forearm. Nature (London). 208: 588.

32. Ross, B. D., R. Hems, and H. A. Krebs. 1967. The rate of gluconeogenesis from various precursors in the perfused rat liver. Biochem. J. 102: 942.

33. Shrago, E., H. A. Lardy, R. C. Nordlie, and D. O. Foster. 1963. Metabolic and hormonal control of phosphoenolpyruvate carboxykinase and malic enzyme in rat liver. J. Biol. Chem. 238: 3188.

34. Freedman, A. D., and L. Kohn. 1964. Pyruvate metabolism and control: factors affecting pyruvic carboxylase activity. Science. 145: 58.

35. Williamson, D. H., O. Lopes-Vieira, and B. Walker. Concentrations of free glucogenic amino acids in liver of rats subjected to various metabolic stresses. Bioch sm. J. $104: 497$.

36. Paleologos, G., E. Muntwyler, and L. Kesner. 1968. Free amino acids of rat tissues under altered conditions of gluconeogenesis. Fed. Proc. 27: 763. (Abstr.) 
37. Saunders, S. J., A. S. Truswell, G. O. Barbezat, W. Wittman, and J. D. L. Hansen. 1967. Plasma free amino acid pattern in protein-calorie malnutrition. Lancet. 2: 795.

38. Krebs, H. A. 1964. The metabolic fate of amino acids. In Mammalian Protein Metabolism. H. N. Munro and J. B. Allison, editors. Academic Press Inc., New York. 1: 163.

39. Pitts, R. F. 1964. Renal production and excretion of ammonia. Amer. J. Med. 36: 720 .
40. Owen, E. E., and R. R. Robinson. 1963. Amino acid extraction and ammonia metabolism by the human kidney during the prolonged administration of ammonium chloride. J. Clin. Invest. 42: 263.

41. Pitts, R. F., and L. A. Pilkington. 1966. The relation between plasma concentrations of glutamine and glycine and utilization of their nitrogens as sources of urinary ammonia. J. Clin. Invest. 45: 86.

42. Pitts, R. F., and W. J. Stone. 1967. Renal metabolism of alanine. J. Clin. Invest. 46: 530. 